\title{
Electropolymerization of (ortho cresol-co-pyrrole) and characterization of the obtained film
}

\author{
S. M. Sayyah ${ }^{1}$, F. Mohamed ${ }^{1}$, M. Shaban ${ }^{2}$, \\ ${ }^{1}$ Polymer Research_lab, Chemistry Department, Faculty of Science, Beni-Suef University, Beni-Suef 62514, \\ Egypt \\ ${ }^{2}$ Nanophotonics and Applications (NPA) Lab, Department of Physics, Faculty of Science, Beni-Suef University, \\ Beni-Suef 62514, Egypt
}

\begin{abstract}
Electrochemical method is a simple one to prepare poly o-methyl phenol-pyrrole P(o-cresol-copyrrole). Effects of different reaction parameters such as temperature, monomer and acid concentrations on the growth of the copolymer are studied by using cyclic voltammetry. The kinetic studies indicate that the orders of the reaction are 2.3and 1.1 for monomer and acid concentrations, respectively. The apparent activation energy is calculated to be $27 \mathrm{~kJ} / \mathrm{mol}$. In addition, the fabricated copolymer is characterized and investigated by ${ }^{I} \mathrm{H}$ NMR, TGA, IR-UV spectroscopy, XRD, SEM and elemental analysis. Moreover, the mechanism of the reaction is proposed and discussed by using Fineman-Ross method.
\end{abstract}

Keyword: Copolymer, pyrrole, orho cresol, cyclic voltammetry

\section{Introduction}

Electropolymerization of conductive polymers such as polypyrrole [1-3] and polyaniline [4,5], as well as electropolymerization of non-conductive polymers, such as poly(phenols), poly ( $m$-phenylenediamine) [6,7] and poly(phenylene oxide) [8,9], have been well studied and is one of the potent methods for fabrication of film that may be used in to guide and deposit biological entities such as enzymes, antibodies, nucleic acids, subcellular fragments, and even whole cells to metallic or semi-conducting electrode sites of more complex devices [10-12].. Polypyrrole is a conductive electroactive polymer electropolymerized from its monomer pyrrole, which, because of its facility to direct the deposition of dopant and entrained macromolecules onto electrode surfaces, has been previously described and reviewed for the fabrication of amperometric, voltammetric, and impedimetric biotransducers [13-15].

While, the electrooxidation of phenol occurs through the formation of the phenoxy radical, which either reacts with other species present in the solution generating products, or react with other phenol molecules producing a dimer radical. This radical can be oxidized following two different paths: the formation of polymers or quinones, depending on the conditions used. For high phenol concentrations and basic medium, polymerization is favored, while for low phenol concentrations and acid medium the formation of quinones is privileged [16,17].

Lack literatures concerning with the electropolymerization of mixture (pyrrole and phenols) in sulfuric acid solution and the probability of its importance in many fields as antimicrobial activities and in adsorption of many heavy metals motivated us to try to study the electropolymerization of (o-cresol-co-pyrrole) on pt electrode in sulfuric acid solution. Also we interested to study the kinetics and optimize the conditions for the electrochemical oxidation of (o-cresol-co-pyrrole) in aqueous $\mathrm{H}_{2} \mathrm{SO}_{4}$ medium as electrolyte. The kinetic studies for this reaction are performed to calculate the orders of reaction with respect to monomer concentration, acid concentration and thermodynamic activation parameters such as enthalpy $\left(\Delta \mathrm{H}^{*}\right)$, entropy $\left(\Delta \mathrm{S}^{*}\right)$ and activation energy ( $\mathrm{Ea})$ for electro-oxidation of copolymer. In addition, various techniques are used to characterize the formed polymer such as thermo gravimetric analysis (TGA), Proton nuclear magnetic resonance $\left({ }^{1} \mathrm{HNMR}\right)$, and UV-IR spectroscopy. In addition, scanning electron microscopy (SEM) and X-ray diffraction (XRD) are used to study the surface morphologies and compositions of P (o-MP-co-pyrrole) formed at different electrolytic composition, current density, and electrode configuration.

\subsection{Materials}

\section{EXPERIMENTAL}

Pyrrole,ortho methy phenol(o-cresol), sulfuric acid solution(Merck) All solutions were prepared by using freshly double-distilled water.

\subsubsection{Electrodes}

\subsubsection{Working electrode}

The working electrode (WE) was a platinum sheet with dimensions of $1 \mathrm{~cm}$ length and $0.5 \mathrm{~cm}$ width. 


\subsubsection{Auxiliary electrode}

The auxiliary (counter) electrode (CE) was a platinum foil with the same dimensions as the WE.

\subsubsection{Reference electrode}

A saturated calomel electrode (SCE) was used as a reference electrode.

Electrochemical experiments were performed using the Potentiostat / Galvanostat Wenking PGS 95.

\subsection{Characterization of the electro-prepared polymers}

\subsubsection{UV-vis, IR and H-NMR spectroscopy, TGA and elemental analysis}

UV-vis. absorption spectra of the prepared polymer sample was measured using Shimadzu UV spectrophotometer (M160 PC) at room temperature in the range 200-400 nm using acetone as a solvent and reference. IR measurements were carried out using shimadzu FTIR-340 Jasco spectrophotometer (Japan) by $\mathrm{KBr}$ pellets disk technique.

${ }^{1} \mathrm{H}-\mathrm{NMR}$ measurements were carried out using a Varian EM 360 L, 60-MHz NMR spectrometer. NMR signals of the electropolymerized sample were recorded in dimethylsulphoxide (DMSO) using tetramethylsilane as internal standard. TGA of the obtained polymer was performed using a Shimadzu DT-30 thermal analyzer (Shimadzu, Kyoto, Japan). The weight loss was measured from ambient temperature up to $600{ }^{\circ} \mathrm{C}$, at the rate of $20^{\circ} \mathrm{C} \mathrm{min}-1$ and nitrogen $50 \mathrm{cc}$ min-1 to determine the degradation rate of the polymer.

Elemental analysis was carried out in the micro-analytical center at Cairo University (Cairo, Egypt) by oxygen flask combustion and dosimat E415 titrator (Metrohm).

\subsubsection{Scanning electron microscopy and X-ray diffraction}

Scanning electron microscopic (SEM) analysis was carried out on the as-prepared polymer film deposited on Pt-working electrode surface using a JSM-T20 Electron Probe Microanalyzer (JEOL, Tokyo, Japan). The X-ray diffraction analysis (XRD) (Philips 1976 Model 1390, Netherlands) was operated under the following conditions that were kept constant for all the analysis processes:

$\mathrm{X}$-ray tube, $\mathrm{Cu}$; scan speed, 8 deg min-1; current, $30 \mathrm{~mA}$; voltage, 40 $\mathrm{kV}$; preset time, $10 \mathrm{~s}$.

\section{RESULT AND DISCUSSION}

\subsection{Electropolymerization of binary mixture of o-cresol and pyrrole:}

Electropolymerization of the two separate monomers (o-cresol), (pyrrole) and the binary mixture of the two monomers with molar ratio $1: 1$ in aqueous acid medium $\left(0.3 \mathrm{H}_{2} \mathrm{SO}_{4}\right)$ at $313 \mathrm{~K}$ was carried out. The obtained voltammograms are represented in "Fig. 1".

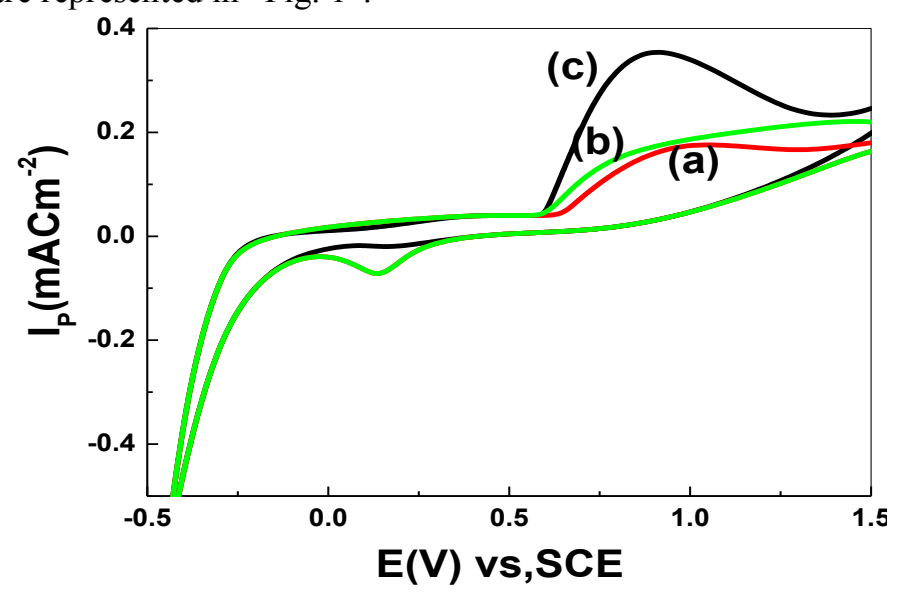

Figure.1. cyclic voltammograms of electropolymerization of (a) $0.07 \mathrm{M}$ pyrrole (b) $0.04 \mathrm{M}$ o-cresol and (c)

$0.05 \mathrm{M}$ of the two monomers solutions containing $0.3 \mathrm{MH}_{2} \mathrm{So}_{4}$ with scan rate $30 \mathrm{mVs}^{-1}$ on pt- electrode.

The data reveals that; the anodic oxidation peaks; at $900 \mathrm{mV}$ vs SCE in case of pyrrole, at $850 \mathrm{mV}$ vs. SCE in case of cresol and at $760 \mathrm{mV}$ vs. SCE in mixture of (o-cresol-co-pyrrole) the anodic peak of comononer is attributed to the combination of the oxidation of two monomers(o-cresol and pyrrole) and react with another molecule of monomer to form dimer radical and so on to form the corresponding the copolymer (o-cresol-copyrrole).

The cathodic span of the reverse scan of the binary monomer mixture has a one cathodic peak appears at $200 \mathrm{mVvs.SCE}$ indicating that the system is reversible and indicating that the copolymer reduced. 


\subsubsection{Effect of scan rate}

Effect of scan rate on the cyclic voltammograms of (o-cresol-co-pyrrole) on Pt electrode is shown in Fig .2". Figure 2(a) shows the cyclic voltammogram of comonomer for scan rate from 10 to $40 \mathrm{mVs}^{-1}$ recorded at pt working electrode for $0.3 \mathrm{M} \mathrm{H}_{2} \mathrm{SO}_{4}$ and $0.05 \mathrm{M}$ of (o-cresol-co-pyrrole) at $313 \mathrm{~K}$. As shown in the figure, the peak current density $\left(\mathrm{I}_{\mathrm{p}}\right)$ increases as the scan rate increased. This behavior may be ascribed to the depletion of the species in the vicinity of the Pt- surface when enough potential is applied to the Ptsurface causing oxidation of species in the solution. As a result, a concentration gradient $(\mathrm{dC} / \mathrm{dx})$ appears in the solution and the peak current $\left(\mathrm{I}_{\mathrm{p}}\right)$ is proportional to the gradient slope $(\mathrm{dC} / \mathrm{dx})$. As the scan rate increased, the gradient increases and consequently the current $\left(I_{p}\right)$ increases. The linear dependency of the anodic peak current density $\left(\mathrm{I}_{\mathrm{p}}\right)$ on the square root of scan rate $\left(\mathrm{V}^{1 / 2}\right)$ is shown in "Fig. 2 (b)" and represented by the linear regression equation:

$$
\mathrm{Ip}_{\text {(II) }}=0.14 \mathrm{~V}^{1 / 2}\left(\mathrm{mVs}^{-1}\right)^{1 / 2}-0.14
$$

From the above equations we noted that correlation coefficient $r=0.926<1$. This linear relation suggests that the electroformation of copolymer may be described by a partially diffusion - controlled process (diffusion of reacting species to the polymer film/solution interface)[18]. I.e., the process is not completely diffusion - controlled but it is exactly a partially diffusion- controlled. It seems that, initially the electroformation of radical cation and free radical is controlled by charge transfer. . The intercept is negative, 0.14 , which could be attributed to a decrease of the active area of the working electrode during the positive scan or the increase of the covered area of working electrode by the adhered polymer layer [19]. When the polymers become thick, the diffusion of reactant inside the film becomes the slowest step and the process changed to charge transfer. Using the values of $I_{p}$ and scan rate, $V\left(V^{-1}\right)$, the diffusion coefficient can be calculated using Randless and Sevick equation [20,21]:

$$
\mathrm{I}_{\mathrm{p}}(\mathrm{II})=0.4463 \text { n F A C }(\text { n F V D / R T })^{1 / 2}
$$

Where $\mathrm{n}$ is the number of exchanged electron in the mechanism, $\mathrm{F}$ is Faraday's constant (96485 C mol), A is the electrode area $\left(\mathrm{cm}^{2}\right), \mathrm{C}$ is the bulk concentration, $\mathrm{D}$ is the analyst diffusing coefficient $\left(\mathrm{cm}^{2} \mathrm{~s}^{-1}\right), \mathrm{R}$ is the universal gas constant $\left(8.134 \mathrm{Jmol}^{-1} \mathrm{~K}^{-1}\right)$, and $\mathrm{T}$ is the absolute temperature $(\mathrm{K})$. The calculated values of $\mathrm{D}$ (at $0.6 \mathrm{M} \mathrm{H}_{2} \mathrm{SO}_{4}$ and $303 \mathrm{~K}$ with scan rate from 10 to $40 \mathrm{mV} \mathrm{s}^{-1}$ ) are shown in "Table 1". The values of $\mathrm{D}$ are seen to be slightly changed over the range of sweep rates, which again shows that the oxidation process is diffusion-controlled [22].

Table 1. The calculated values of diffusion coefficients for different scan rates.

\begin{tabular}{|c|c|}
\hline Scan rate $\left(\mathrm{Vs}^{-1}\right)$ & $\begin{array}{c}\text { Diffusing coefficient, }\left(\mathrm{m}^{2} \mathrm{~s}^{-1}\right) \\
\text { (o-cresol and pyrrole } \rightarrow \mathrm{P}(\mathrm{cresol}-\mathrm{co}-\mathrm{pyrrole})\end{array}$ \\
\hline 0.01 & $1.1 \times 10^{-9}$ \\
\hline 0.020 & $1.4 \times 10^{-9}$ \\
\hline 0.030 & $3.3 \times 10^{-9}$ \\
\hline 0.040 & $9.2 \times 10^{-9}$ \\
\hline
\end{tabular}
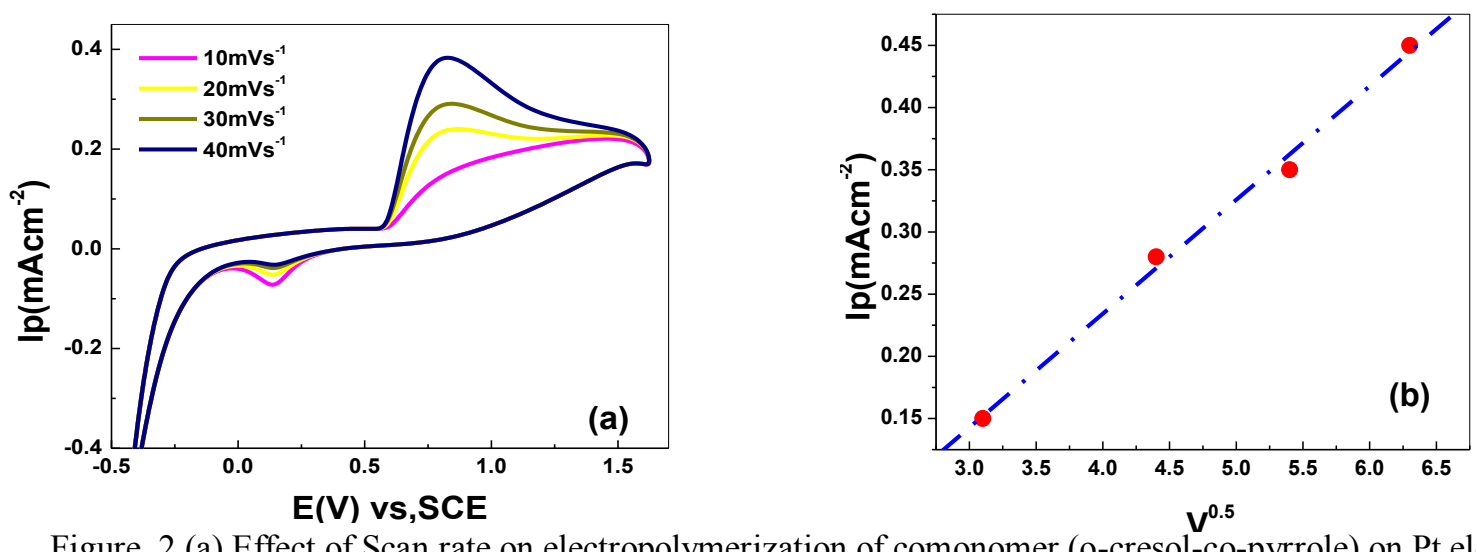

Figure. 2.(a) Effect of Scan rate on electropolymerization of comonomer (o-cresol-co-pyrrole) on Pt electrode from solution containing $0.3 \mathrm{M} \mathrm{H}_{2} \mathrm{SO}_{4}$ at $313 \mathrm{~K}$. (b). Relation between $\mathrm{i}_{\mathrm{pII}}$ and square root of scan rate. 


\subsubsection{Effect of number of cycles}

In order to examine the electrode stability, six repetitive cyclic voltammograms in a solution containing $0.05 \mathrm{M}$ of (o-cresol-co-pyrrole) in $0.3 \mathrm{H}_{2} \mathrm{SO}_{4}$ with scan rate $30 \mathrm{mVs}^{-1}$ at $313 \mathrm{~K}$ were performed. As seen in" Fig 3". The current involved in the oxidation of commoner decreases gradually as the number of cycles increased. This decrease in anodic peak with increasing the thickness of film due to decrease in conductivity and also the rate of diffusion within the film decreases.
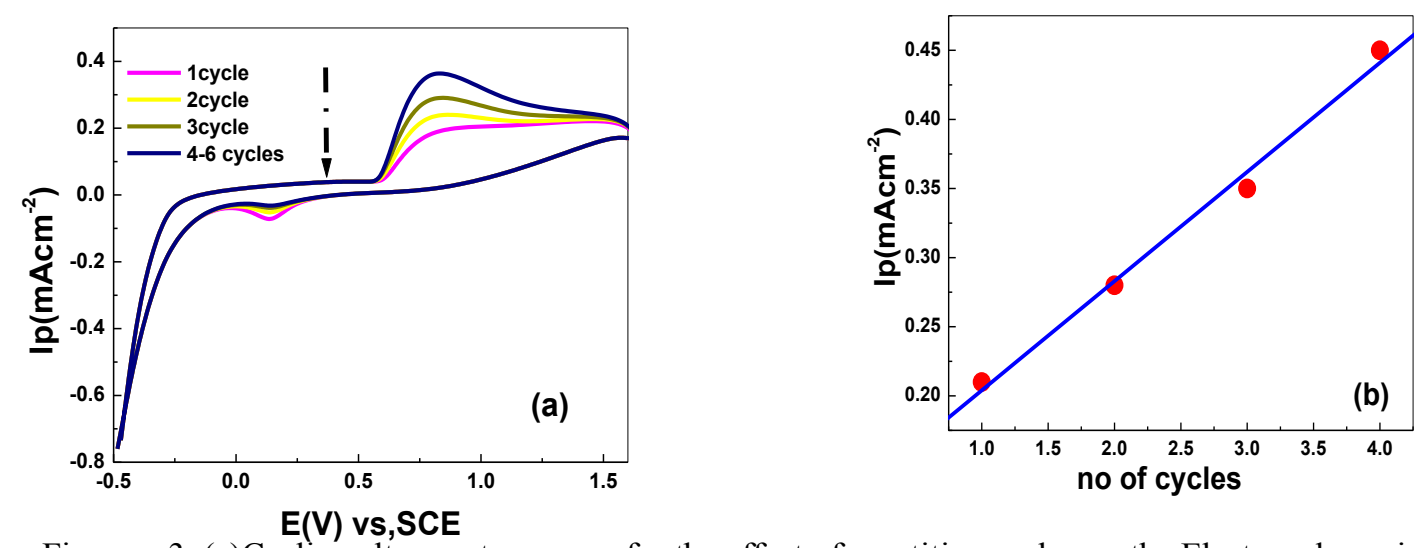

Figure . 3. (a)Cyclic voltammetry curves for the effect of repetitive cycles on the Electropolymerization of $0.05 \mathrm{M}$ (o-cresol-co-pyrrole) from solution containing $0.3 \mathrm{MH}_{2} \mathrm{SO}_{4}$ at $313 \mathrm{~K}$ with scan rate $30 \mathrm{mVs}^{-1}$ on pt Electrode (b) the relation of Ip and no of cycle.

\subsubsection{Kinetic studies}

The electropolymerization kinetics was investigated by using aqueous solution containing (comonomer (ocresol-co-pyrrole) concentration in the range between 0.01 and $0.05 \mathrm{M}$ where $\mathrm{H}_{2} \mathrm{SO}_{4}$ concentration in the range between 0.05 and $0.4 \mathrm{M}$ at $313 \mathrm{~K}$. The cyclic voltammogram for each comonomeric system and the relation between the $\log i_{\mathrm{pII}} \mathrm{VS} \log$ [monomer conc.] or $\log \mathrm{i}_{\mathrm{pII}} \mathrm{VS} \log \left[\mathrm{H}_{2} \mathrm{SO}_{4}\right.$ Conc.] are studied to obtain the order of the reaction.

\subsubsection{Effect of comonomer concentration on the electropolymerization processes:}

Figure 4(a) shows the cyclic voltammograms of comonomer at different concentrations $(0.01-0.05 \mathrm{M})$ in the presence of $0.3 \mathrm{M} \mathrm{H}_{2} \mathrm{SO}_{4}$ recorded at a scan rate $30 \mathrm{mVs}^{-1}$, From the voltammogram, the oxidation peak of comonomer appears at an electrode potential of about $0.76 \mathrm{~V}$. The peak current $\left[\mathrm{i}_{\mathrm{p}}\right]$ increases as the comonomer concentration increased to reach the maximum value and then decrease for comonomer concentration than $>$ $0.04 \mathrm{M}$ ). This behavior may be attributed to the decrease in the activity of the pt electrode at higher monomer concentrations or due to competition for the active sites on the electrode surface as a result of the formation of a large number of radical cations and free radicals during the electropolymerization process. While the cathodic peak appears at. $0.15 \mathrm{~V}$ which attributed to the reduction of the copolymer film of $\mathrm{p}$ (o-cresol-co-pyrrole). For different comonomer concentrations, the anodic peak current density $\left[i_{p}\right]$ is directly proportional to the concentration and a linear realtion is obtained. The order of reaction was obtained from the slop the linear fitting to be 2.3 , as shown in "Fig. 4"
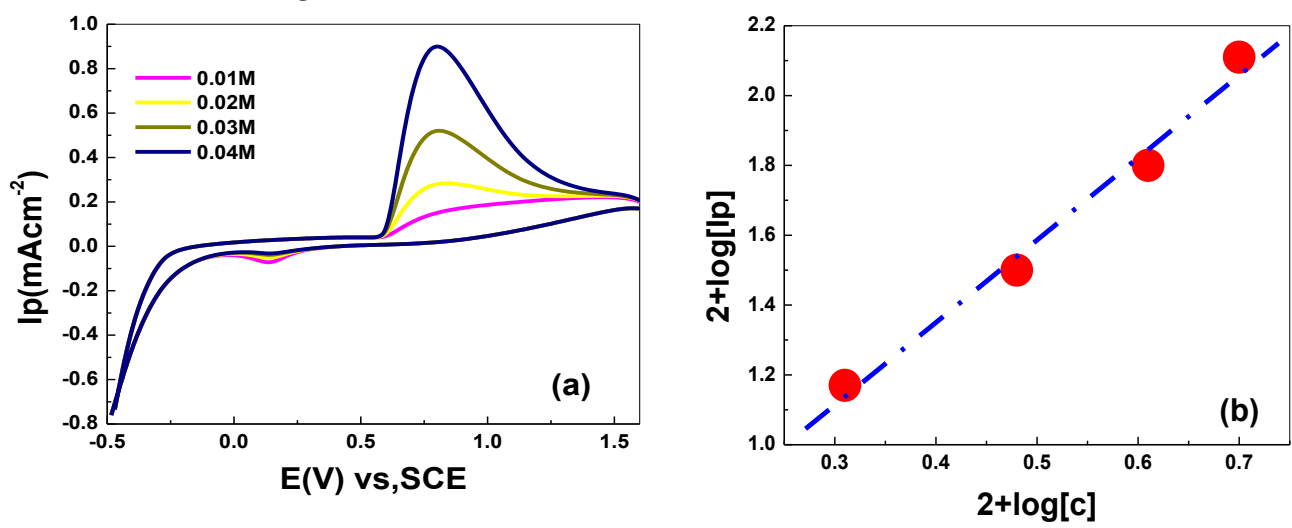

Figure .4.(a)Cyclic voltammetry curves for the effect of (o-cresol-co-pyrrole) concentration on the Electropolymerization of pyrrole from solution containing $0.3 \mathrm{MH}_{2} \mathrm{SO}_{4}$ at $313 \mathrm{~K}$ with scan rate $30 \mathrm{mVs}^{-1}$ on pt Electrode (b) Double logarithmic plot of $\mathrm{i}_{\mathrm{p} 1} \mathrm{vs}$, comonomer concentrations. 


\subsubsection{Effect of $\mathrm{H}_{2} \mathrm{SO}_{4}$ concentration on the polymerization process}

Experiments were performed to study the effect of $\mathrm{H}_{2} \mathrm{SO}_{4}$ concentration on the electropolymerization process. This effect is shown in" Fig 5(a) "which represents cyclic voltammograms obtained in $0.05 \mathrm{M}$ of (ocresol-co-pyrrole) at a scan rate $30 \mathrm{mVs}^{-1}$ with a temperature $313 \mathrm{~K}$ at different acid concentrations from 0.05 to $0.4 \mathrm{M}$. The height of peak current increases with increasing the acid concentration up to $0.3 \mathrm{M}$ and then decreasing at $0.4 \mathrm{M}$ as a result of degradation of the copolymer film. This agree well with the well known rule that the polymerization process is favored at low $\mathrm{PH}$ [23].The order of reaction with respect of sulfuric acid concentration was found to be 1.1 from the slope of the linear relation between peak current and acid concentration as shown in "Fig.5(b)".
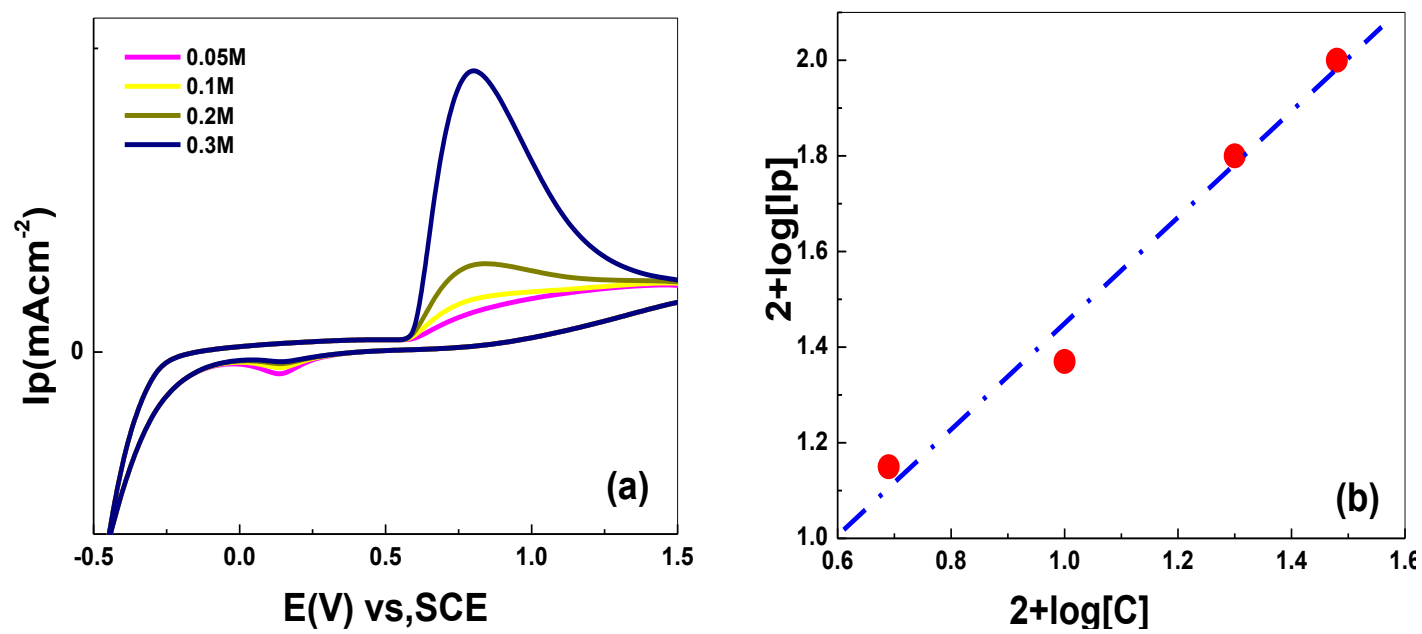

Figure.5. (a) Cyclic voltammetry curves for the effect of $\mathrm{H}_{2} \mathrm{SO}_{4}$ concentration on the Electropolymerization of comonomer from solution containing 0.05 (o-cresol-co-pyrrole) at $313 \mathrm{~K}$ with scan rate $30 \mathrm{mVs}^{-1}$ on pt Electrode and (b) Double logarithmic plot of $i_{p 1}$ vs, acid concentrations.

\subsubsection{Effect of temperature and calculation of thermodynamic parameters:}

The effect of temperature on the process is represented in "Fig. 6". The potentiodynamic profiles of $0.05 \mathrm{M}$ of (o-cresol-co-pyrrole) in a solution containing $0.3 \mathrm{M} \mathrm{H}_{2} \mathrm{SO}_{4}$ at different temperatures from 283 to $313 \mathrm{~K}$ is shown in "Fig .6 (a)". As shown the reaction strongly depends on the temperature and Ip increases with increasing the temperature. Reaction activation energy is calculated by plotting relation between logarithm of peak current and reciprocal of absolute temperature as shown in "Fig. 6 (b)". Straight line is obtained and the activation energy is calculated from the Erying equation [24]:

$$
E_{a}=-2.303 \times 8.314 \times \text { slope of reaction }
$$

1000

Then it to be equal to $27 \mathrm{~kJ} / \mathrm{mole}$

The enthalpy $\Delta \mathrm{H}^{*}$ and entropy $\Delta \mathrm{S}^{*}$ of activation for the electropolymerization reaction can be calculated from Eyring equation [262].plot at different temperatures "Fig. 6(c)". This result in linear relationships with slope equal to $\Delta \mathrm{H}^{*} / 2.303 \mathrm{R}$ and intercept equal to $(\mathrm{R} / \mathrm{Nh})+\Delta \mathrm{S}^{*} / 2.303 \mathrm{R}$. From the slope and intercept values, $\Delta \mathrm{H}^{*}$ and $\Delta \mathrm{S}^{*}$ for pyrrole are calculated to be $17.9 \mathrm{~kJ} \mathrm{~mol}^{-1}$ and $12.6 \mathrm{JK}^{-1} \mathrm{~mol}^{-1}$, respectively.

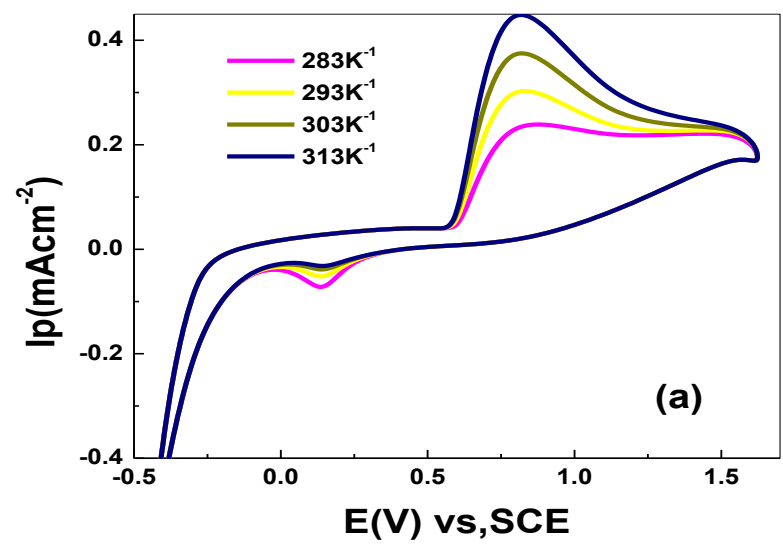



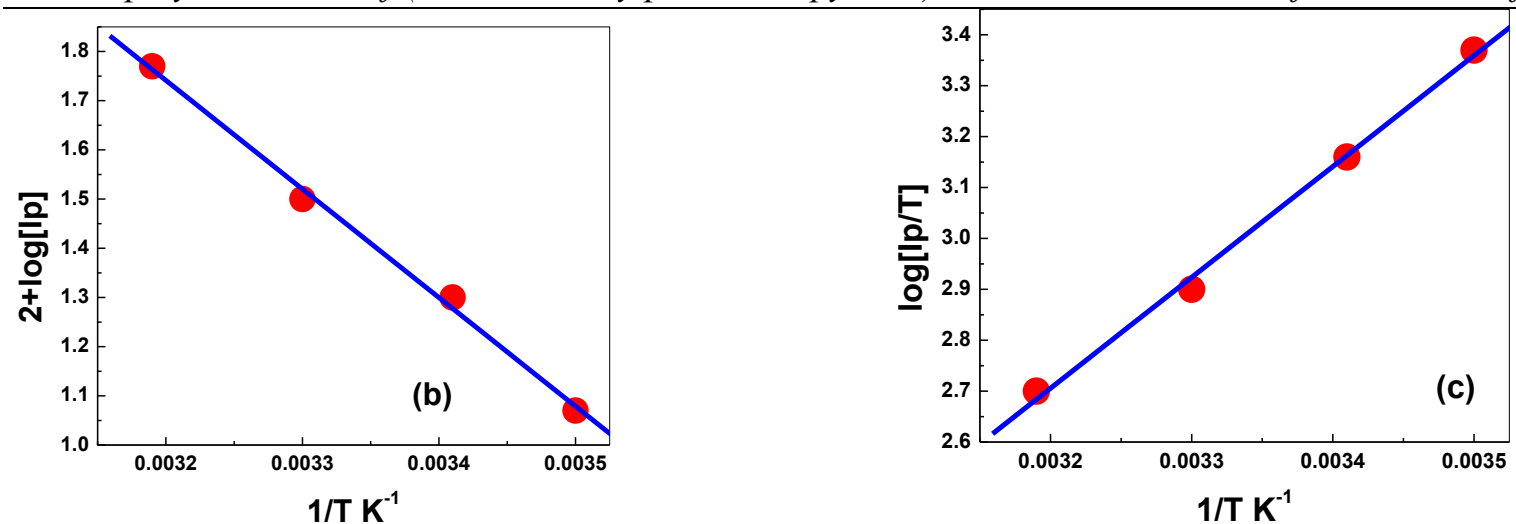

Figure. 6.(a) Cyclic voltammetry curves for the effect of temperature on the electropolymerization,(b) Arrhenius plot and (c) Eyring equation plot.

\subsubsection{Copolymer structure and mechanism:}

The monomer reactivity ratios of the copolymerization system $\left(\mathrm{r}_{1} \mathrm{andr}_{2}\right)$ involving o-Methylphenol (ocresol) and Pyrrole were determined on the basis of comonomer composition -copolymer composition relationship the copolymer composition of each sample was calculated according to the nitrogen content as follows:

Nitrogen content of copolymer $=$ molecular weight of $\mathrm{M}_{1}$

Nitrogen content of $\mathrm{M}_{1} \quad$ molecular weight of $\mathrm{M}_{1}+$ molecular weight of $\mathrm{M}_{2} / \mathrm{b}$

Where $\mathrm{M}_{1}$ is the Nitrogen containing monomer (pyrrole) and $\mathrm{b}=\mathrm{m}_{1} / \mathrm{m}_{2}$ is the molar ratios of copolymer composition.

The monomer reactivity ratios were calculated according to fineman-Ross method [25]. Using $\mathrm{N} —$ content as a quantitative analytical tool.

\subsubsection{Fineman-Ross method:}

Two monomers are incorporated into the copolymer chain depending on their relative concentrations and reactivities. The composition of the copolymer was quantitively determined by $\mathrm{N}$ content in the copolymer samples and the data are given in" Table 2." The monomer reactivity ratios $r_{1} a_{n} d_{2}$ of this copolymer was calculated from Fineman-Ross equation "Eq.4" and represented in "Fig. 7"

$$
\mathrm{F} / \mathrm{f}(\mathrm{f}-1)=\mathrm{r}_{1}\left(\mathrm{~F}^{2} / \mathrm{f}\right)-\mathrm{r}_{2}
$$

Where,

$\mathrm{F}=\mathrm{M}_{1} / \mathrm{M}_{2}$ (molar ratio for monomer feed composition)

$\mathrm{f}=\mathrm{m}_{1} / \mathrm{m}_{2}$ (molar ratio for copolymer composition)

Table 2. Reactivity ratio data for o-cresol $\left(\mathrm{M}_{1}\right)$ and Pyrrole $\left(\mathrm{M}_{2}\right)$ in electropolymerization reaction system.

\begin{tabular}{|c|c|c|c|c|c|c|}
\hline \multirow{2}{*}{\multicolumn{2}{|c|}{$\begin{array}{c}\text { Initial monomer concentration mole } \\
\text { fraction } \\
\text { Mole fraction } \\
\end{array}$}} & \multirow{3}{*}{ N\% } & \multicolumn{2}{|c|}{$\begin{array}{c}\text { Copolymer } \\
\text { composition } \\
\text { using N-content }\end{array}$} & \multirow{3}{*}{$\mathrm{F}^{2} / \mathrm{f}$} & \multirow[b]{3}{*}{$\mathrm{F} / \mathrm{f}(\mathrm{f}-1)$} \\
\hline & & & \multirow[b]{2}{*}{$\mathrm{m}_{1}$} & \multirow[b]{2}{*}{$\mathrm{m}_{2}$} & & \\
\hline $\begin{array}{c}\mathrm{M}_{1} \\
\text { Cresol }\end{array}$ & $\begin{array}{c}\mathrm{M}_{2} \\
\text { Pyrrole }\end{array}$ & & & & & \\
\hline 0.1 & 0.9 & 9.9 & 0.407 & 0.592 & 0.0179 & -0.0347 \\
\hline 0.3 & 0.7 & 8.1 & 0.495 & 0.504 & 0.1795 & 0.00769 \\
\hline 0.5 & 0.5 & 5.9 & 0.6121 & 0.45 & 0.634 & 0.365 \\
\hline 0.7 & 0.3 & 5.7 & 0.62 & 0.381 & 3.35 & 0.88 \\
\hline 0.9 & 0.1 & 3 & 0.96 & 0.08 & 34.07 & 5.2 \\
\hline
\end{tabular}




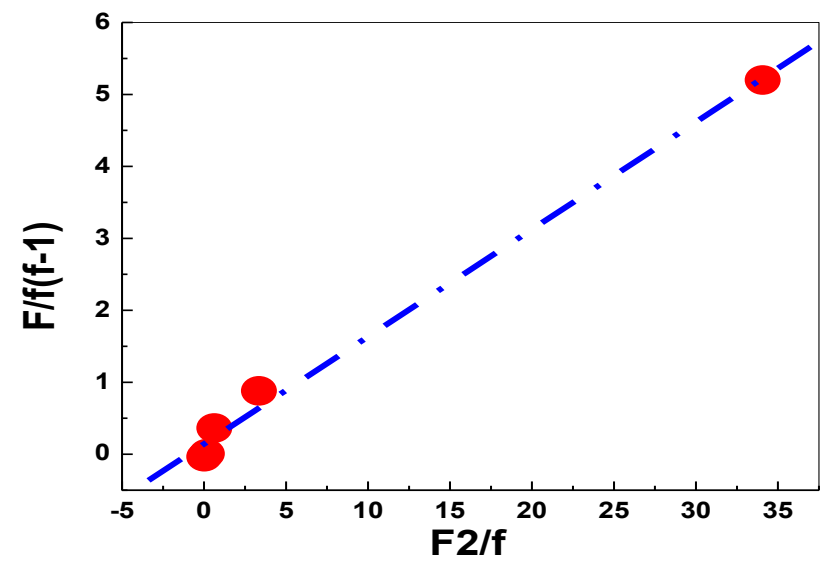

Figure. 7.Fineman -Ross plot for the determination of monomer reactivity ratio of o-cresol and Pyrrole in sulfuric acid as supporting electrolyte copolymerized by electrochemical method on pt electrode.

The slope is equal to $r_{1}$ and the intercept is equal to $-r_{2}$. From the Figure, it was found that $r_{1}=0.14 \operatorname{andr}_{2}=$ 0.15 . From the data, the value of $r_{1}$ is less than one and $r_{2}$ is less than one. In this case the propagation type 12 and 21 will be preferred than the type 11 and 22, hence the probability of adding $\mathrm{M}_{2}$ (pyrrole) onto $\mathrm{M}_{1}$ ( o-cresol) and $\mathrm{M}_{1}$ onto $\mathrm{M}_{2}$ takes place at same time. The copolymer composition data for the investigated system were calculated and the relation between the mole fractions of $\mathrm{M}_{2}$ in the formed copolymer $\left(\mathrm{n}_{2}\right)$ and the mole fraction of $\mathrm{M}_{2}$ in monomer feed $\left(\mathrm{N}_{2}\right)$ and are represented in "Fig. 8"

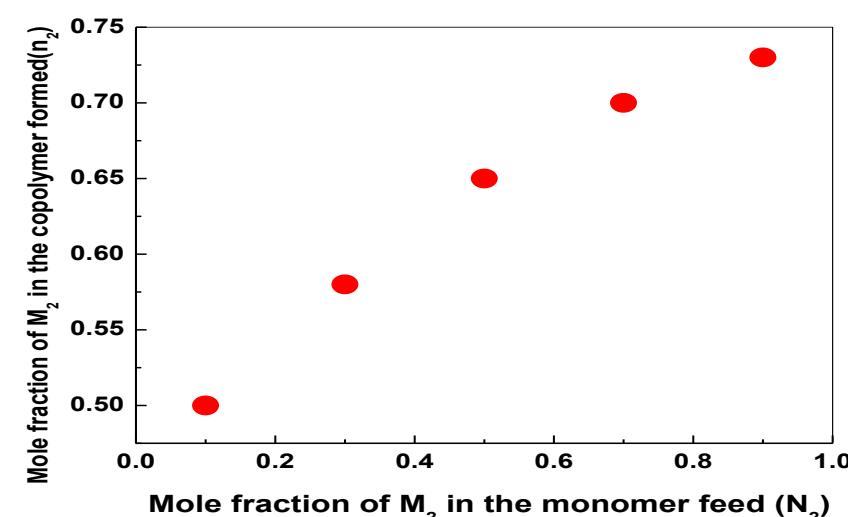

Figure. 8. composition curve for the electropolymerization between (o-cresol) $M_{1}$ and (pyrrole) $M_{2}$ in sulfuric acid solution on pt electrode.

The diagonal line represents the case that both monomers have identical reactivity. The values of $\mathrm{n}_{2}$ for the copolymer are under the diagonal line indicating that the copolymers consist of a same fraction of Pyrrole units and o- cresol units. From the above data, it is clear that the copolymer structure is a block copolymer structure; therefore the copolymerization mechanism can be represented as shown in<smiles>Cc1ccccc1O</smiles>

phenolate<smiles>Cc1ccccc1[O-]</smiles>

phenolate<smiles>Cc1ccccc1[O-]</smiles>

phenoxy radical

(A) 


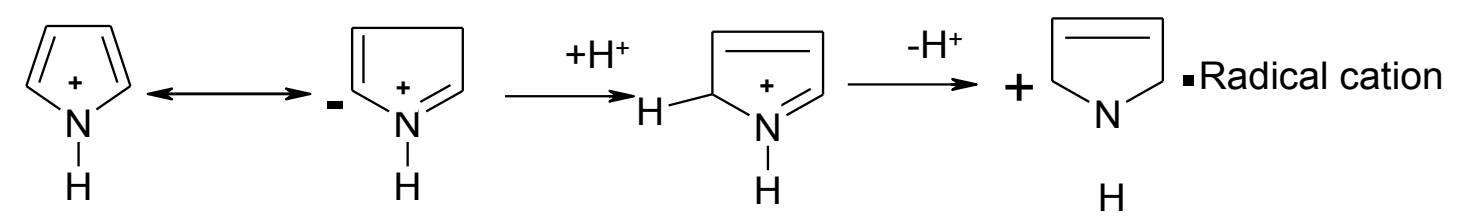

(B)

A+<smiles>Cc1ccccc1O</smiles><smiles>CC1=CC(Oc2ccccc2C)C=C[C]1O</smiles><smiles>Cc1ccc(Oc2ccc(Oc3ccc(Oc4ccc(Oc5ccc(O)c(C)c5)c(C)c4)cc3C)cc2C)cc1C</smiles>

(C) 


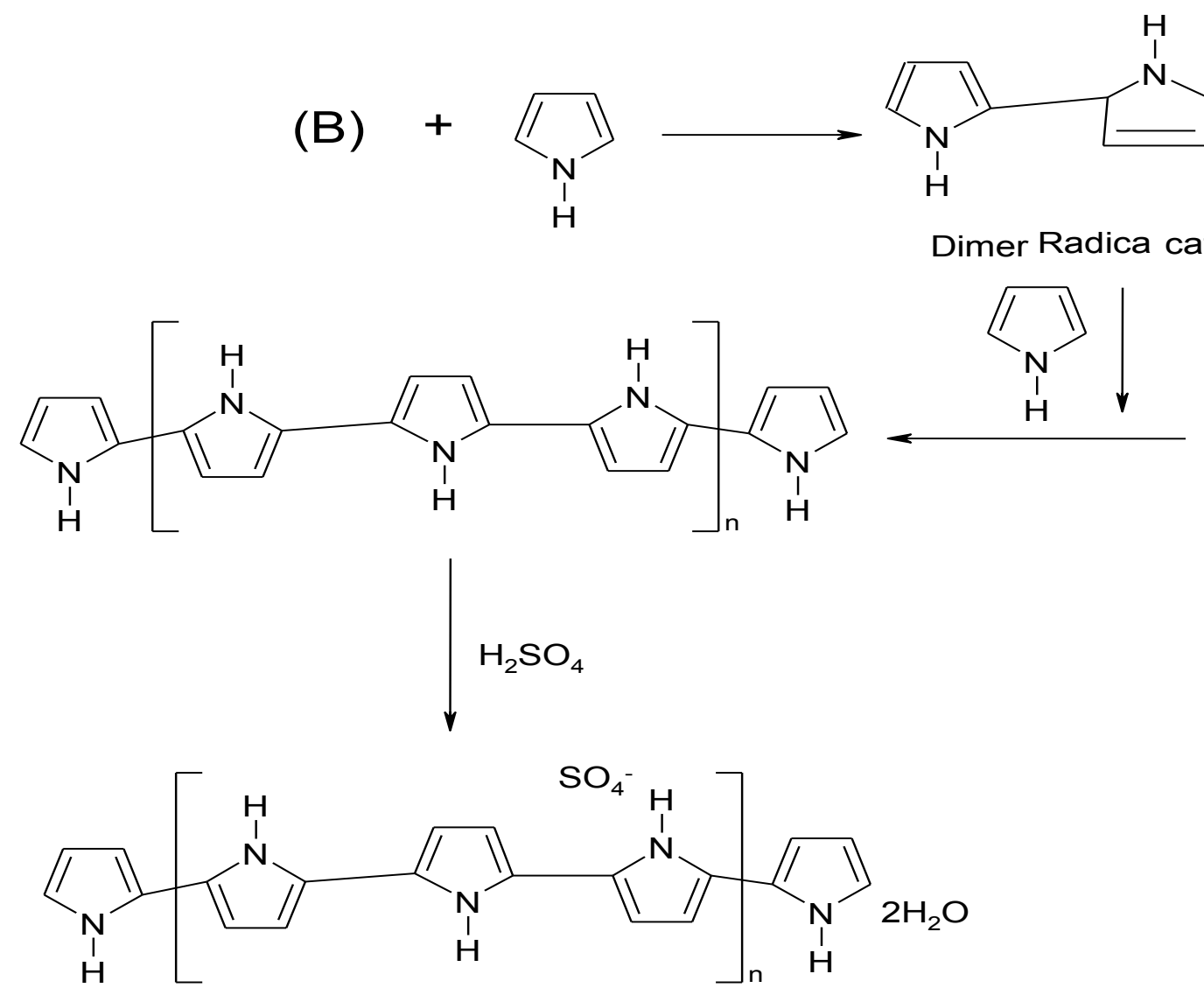

(D)

$\mathbf{C}+\mathbf{D}$

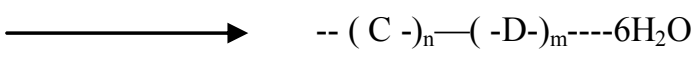

Scheme (1); the formation of radical ion for o-cresol and pyrrole.

\subsection{Characterization of copolymer}

\subsubsection{Elemental analysis}

Elemental analysis of the prepared $\mathrm{P}$ (o-cresol-co-pyrrole) is carried out in the micro- analytical laboratory a Cairo University. The percentage of $\mathrm{C}, \mathrm{H}, \mathrm{N}$ and $\mathrm{S}$ for the investigated sample where the percentage of carbon in the sample is found to be (56\%) which is in a good agreement with the calculated value $(55.5 \%)$, while the $\mathrm{H}$ content in the sample is found to be $5 \%$ which is in a good agreement with the calculated value (5.5\%), in addition the Nitrogen content in sample is found to be $10 \%$ which is in a good agreement with the calculated value (10.4\%), and the sulfur content in sample is found to be $3 \%$ which is in a good agreement with the calculated value (3.5\%) in the polymer. The obtained elemental analysis is in a good agreement with the calculated data for the suggested structure in schemel.

\subsubsection{The UV vis spectra of p(o-cresol-co-pyrrole)}

The ultraviolet-visible spectra of P(o-cresol-co-Pyrrole) are represented in" Fig. 9" The spectra show the following absorption bands.

1-three absorption bands appears at $\lambda_{\max }=240$ and $250 \mathrm{~nm}$ which could be attributed to $\pi$ - $\pi^{*}$ transition ( $\mathrm{E}_{2}$ band) of the benzene ring and the $\beta$-band $\left(\mathrm{A}_{1 \mathrm{~g}}\right.$ to $\left.\mathrm{B}_{2 \mathrm{u}}\right)$.

2-Ashoulder appear at $\lambda_{\max }=330 \mathrm{~nm}$ which could be attributed to the conjugation of the aromatic polymeric chain 


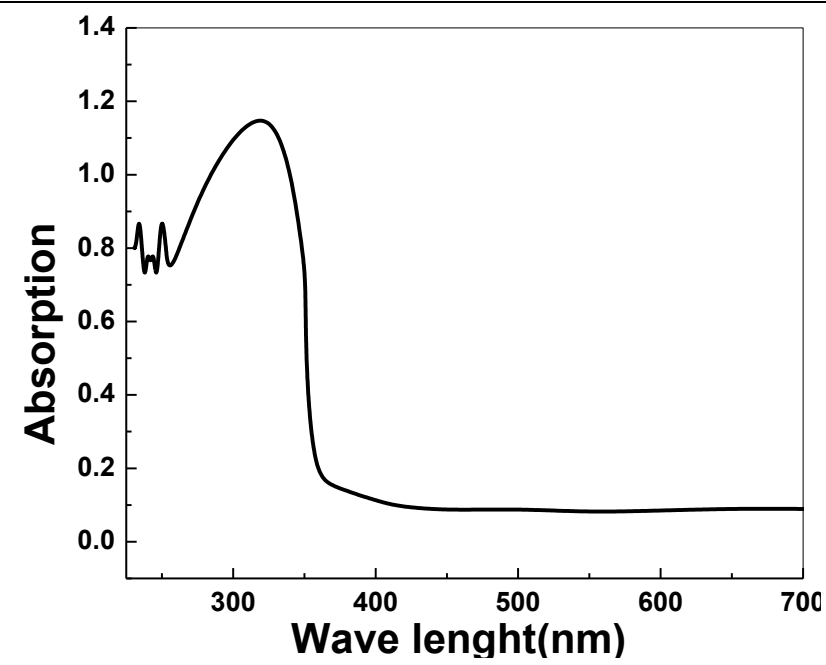

Figure. 9.UV-Vis spectra of p(o-cresol-co-pyrrole).

\subsubsection{Comparative IR spectroscopic studies of the prepared $\mathbf{P}(0$-cresol-co-pyrrole) with $p(0$-cresol)} andp(pyrrole):

The IR spectra of the prepared $\mathrm{P}(\mathrm{o}-$ cresol-co-Pyrrole $), \mathrm{P}(\mathrm{o}-$-cresol $)$ and $\mathrm{P}($ pyrrole $)$ are represented in "Fig. 10 ". From the figure, it is clear that two medium absorption bands appearing at 782 and $884 \mathrm{~cm}^{-1}$ in case of $\mathrm{p}$ (pyrrole) which could be attributed to Stretching vibration of $\mathrm{N}-\mathrm{H}$ in pyrrole ring, appears as a strong absorption peak at $790 \mathrm{~cm}^{-1}$ in case of copolymer. A medium absorption band appear at 1160 and a strong absorption band at $1042 \mathrm{~cm}^{-1}$ in case of $\mathrm{P}($ pyrrole $)$ and $\mathrm{P}($ o-cresol-co-pyrrole $)$ respectively may be due to doping with sulphate ions. absorption bands appearing at $2922,3055,2922 \mathrm{~cm}^{-1}$ in case of $\mathrm{P}$ (pyrrole), p(ocresol) and o-(cresol-co-pyrrole) respectively due to $\mathrm{C}-\mathrm{H}$ stretching vibration of aromatic ring. Broad absorption band appears at $3432 \mathrm{~cm}^{-1}$ in case of $\mathrm{P}($ pyrrole) is attributed to NH starching vibration in pyrrole ring .but in case of $\mathrm{p}\left(\mathrm{o}\right.$-cresol) , a broad absorption peak appears at $3425 \mathrm{~cm}^{-1}$ which could be attributed to stretching vibration intermolecular hydrogen solvated $\mathrm{OH}$ group or end group $\mathrm{OH}$ of polymeric chain.. The other IR absorption bands and their assignments are given in "Table 3"

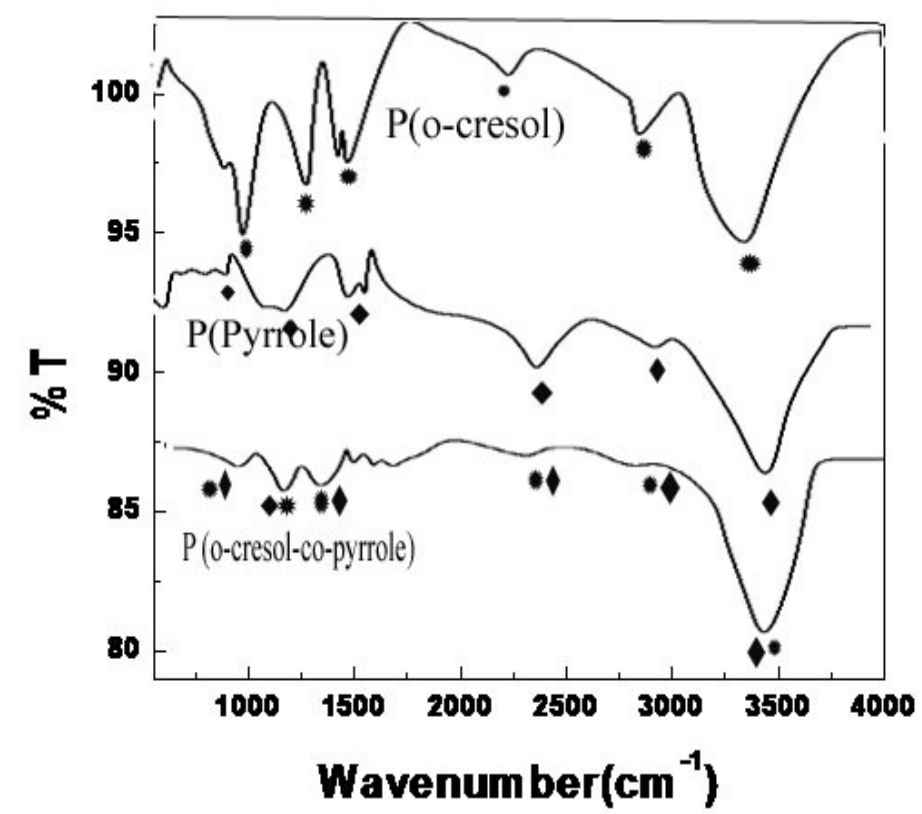

Figure. 10. Comparative IR spectroscopic studies of the prepared P(o-cresol-co-pyrrole) with $\mathrm{p}(\mathrm{o}-\mathrm{cresol})$ and $\mathrm{p}$ (Pyrrole). 
Table 3. Infrared absorption bands of IR spectrum of $\mathrm{P}(\mathrm{o}-\mathrm{cresol}), \mathrm{p}(\mathrm{Pyrrole})$ and $\mathrm{P}(\mathrm{o}-\mathrm{cresol}-\mathrm{co}-\mathrm{pyrrole})$ samples.

\begin{tabular}{|c|c|c|c|}
\hline Polypyrrol-e & $\begin{array}{l}\mathrm{P}(\mathrm{o}- \\
\text { cresol })\end{array}$ & $\begin{array}{l}\mathrm{p}(\mathrm{o}-\mathrm{cresol}-\mathrm{co}- \\
\text { pyrrole })\end{array}$ & Assignment \\
\hline $\begin{array}{l}782^{\mathrm{m}} \\
884^{\mathrm{m}}\end{array}$ & …......... & $790^{\mathrm{s}}$ & $\begin{array}{l}\text { Stretching vibration of } \mathrm{N}-\mathrm{H} \text { in } \\
\text { pyrrole ring }\end{array}$ \\
\hline & $\begin{array}{c}819^{\mathrm{w}} \\
876.5^{\mathrm{w}}\end{array}$ & $904^{\mathrm{m}}$ & $\begin{array}{l}\mathrm{CH} \text { out of plane for tri } \\
\text { substituted benzene ring }\end{array}$ \\
\hline $1160^{\mathrm{m}}$ & & $11044^{\mathrm{m}}$ & $\begin{array}{c}\mathrm{SO}_{4}^{-2} \text { incorporated in polymeric } \\
\text { chain }\end{array}$ \\
\hline \multirow[t]{2}{*}{$1315^{\mathrm{w}}$} & & $1167^{\mathrm{b}}$ & C-N skeletal in pyrrole ring \\
\hline & $\begin{array}{l}1112^{\mathrm{w}} \\
1191^{\mathrm{s}}\end{array}$ & $1100^{\mathrm{m}}$ & C-O stretching vibration \\
\hline $1637^{\mathrm{m}}$ & $\begin{array}{l}1483^{\mathrm{s}} \\
1606^{\mathrm{m}}\end{array}$ & $\begin{array}{l}1454^{\mathrm{m}} \\
1629^{\mathrm{m}}\end{array}$ & Stretching vibration of $\mathrm{C}=\mathrm{C}$ \\
\hline -------- & $2923.5^{\mathrm{m}}$ & $2354^{\mathrm{m}}$ & Methyl group \\
\hline $2922 w$ & $3055^{\mathrm{m}}$ & $2922.7^{\mathrm{w}}$ & $\begin{array}{l}\text { Streching vibration for } \mathrm{CH} \text { of } \\
\text { aromatic ring }\end{array}$ \\
\hline $3432^{b}$ & & $3432.6^{b}$ & $\begin{array}{l}\text { Stretching for NH in pyrrole } \\
\text { ring }\end{array}$ \\
\hline $\begin{array}{ll}------- \\
\end{array}$ & $3425^{\mathrm{b}}$ & ------------------ & $\begin{array}{c}\text { Stretching vibration } \\
\text { intermolecular hydrogen } \\
\text { solvated OH group or end group } \\
\text { OH of polymeric chain }\end{array}$ \\
\hline ……… & $\ldots \ldots \ldots \ldots$ & $3432.6^{b}$ & $\begin{array}{l}\text { Overlapping between } \mathrm{O}-\mathrm{H} \\
\text { solvated in } \mathrm{p}(\mathrm{o}-\mathrm{cresol}) \text { and } \mathrm{N}-\mathrm{H} \\
\text { stretching vibration of } \\
\text { polypyrrole ring }\end{array}$ \\
\hline
\end{tabular}

Where; s: strong,w:weak,b :broad,m:medium

\subsection{4. ${ }^{1}$ HNMR of $P$ (o-cresol-co-pyrrole)}

The ${ }^{1}$ HNMR spectrum of prepared $p$ (o-cresol-co-pyrrole) is not detected as a result of the decrease of copolymer solubility in chloroform or DMSO.

\subsubsection{TGA of poly (o-cresol-co- pyrrole)}

Thermogravimetric analysis (TGA) for the electrochemically prepared $\mathrm{P}$ (o-cresol-co-pyrrole) sample has been investigated and the TGA-curve is represented in "Fig. 11"The presence of six water molecules for each repeated unit is confirmed by thermogravimetric analysis. The TGA steps of the prepared $\mathrm{P}(\mathrm{o}$-cresol-copyrrole) are shown in "Fig. 11" from which it is clear that there are five stages during thermolysis of the copolymer sample. These stages were summarized in "Table 4"

-The first stage : including the loss of 4 molecules of $\mathrm{H}_{2} \mathrm{O}$ in the temperature range between $25^{\circ} \mathrm{C}$ and $225^{\circ} \mathrm{C}$, The weight loss was found to be (7.8\%) which is in good agreement with the calculated value (7.2\%)

The second stage: includes the loss of the dopant species $\mathrm{So}_{3}$ and two molecules of $\mathrm{H}_{2} \mathrm{O}$ in the temperature range between $225^{\circ} \mathrm{C}$ and $350^{\circ} \mathrm{C}$, the weight loss for this step was found to be $12.7 \%$ which is in good agreement with the calculated value (12.5\%)

The third stage: in the range of temperature $350^{\circ} \mathrm{C}$ to $450^{\circ} \mathrm{C}$, includes three units of pyrrole, The weight loss for this step was found to be (22\%)which is in good agreement with the calculated value (22\%)

The fourth step: includes the loss one of benzenoid ring and one pyrrole unit, the weight loss for this step was found to be $(20.5 \%)$ which is in good agreement with the calculated value $(21 \%)$ in the range of temperature $450^{\circ} \mathrm{C}$ to $600^{\circ} \mathrm{C}$.

The fivth step: above $600^{\circ} \mathrm{C}$ includes the remained carbon chain and metallic residue, the weight loss for this step was found $(35 \%)$. 


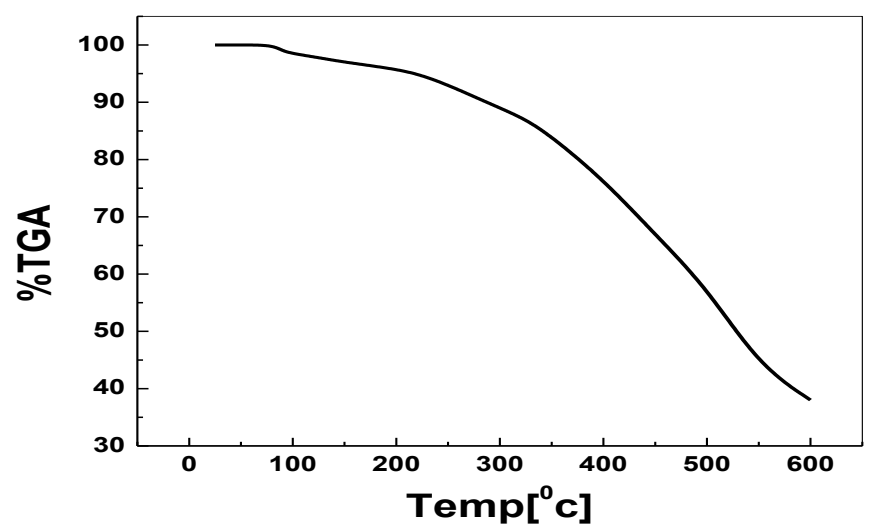

Figure. 11.TGA of poly (o-cresol-co-pyrrole).

Table 4. TGA data of the prepared P (o-cresol-co-pyrrole).

\begin{tabular}{|c|rr|c|}
\hline Temperature range $\left({ }^{\circ} \mathrm{C}\right)$ & \multicolumn{2}{|c|}{ Weight loss (\%) } & \multirow{2}{*}{ The removed molecules } \\
\cline { 2 - 3 } & Calculated experiment & \\
\hline $25-225$ & 7.2 & 7.8 & $4 \mathrm{H}_{2} \mathrm{O}$ \\
\hline $225-350$ & 12.5 & 12.7 & $\mathrm{SO}_{3}, 2 \mathrm{H}_{2} \mathrm{O}$ \\
\hline $350-450$ & 22 & 22 & 3 pyrrole units \\
\hline $450-600$ & 21 & 20.5 & benzenoid ring, one pyrrole \\
\hline$>600$ & 34.2 & 35 & Remaining polymeric chain \\
\hline
\end{tabular}

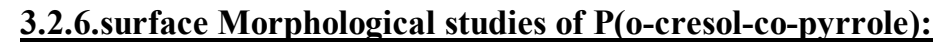

The surface morphology of the copolymer obtained at the optimum conditions was examined by scanning electron microscopy. "Fig. 12" shows top- view FE-SEM image of the electropolymerized film on Pt electrode. As shown in this figure, the morphology of the $\mathrm{p}$ (o-cresol-pyrrole) surface was represented as a small aggregates of random size with a diameter range from $200-400 \mathrm{~nm}$.

In order to check the chemical composition of the fabricated $\mathrm{p}$ (o-cresol-co-pyrrole) the sample was analyzed by XRD as shown in "Fig. 12 (b)" . The XRD pattern in "Fig. 12 (b) " indicate that the copolymer is amorphous.

(b)

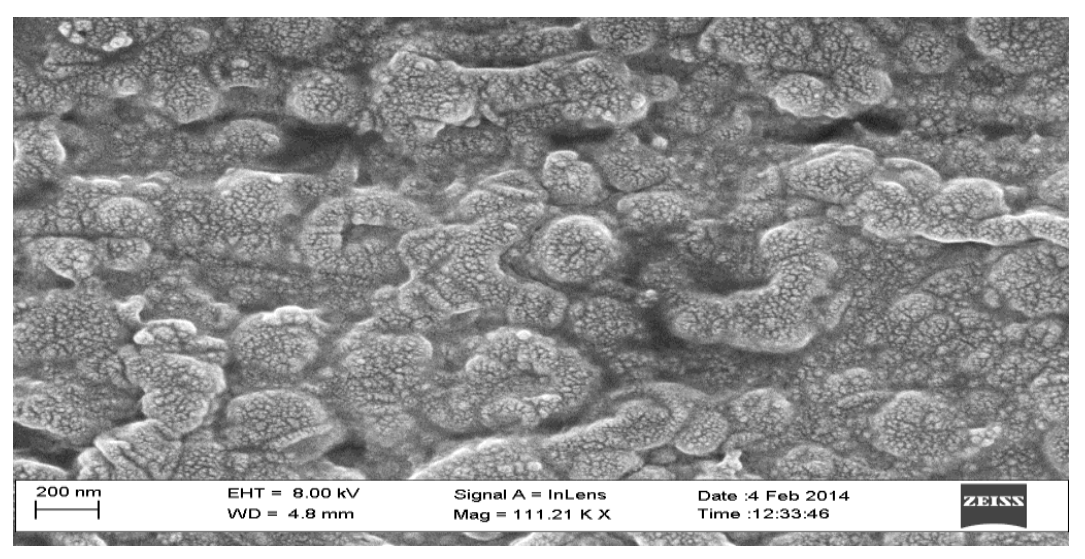

(a)

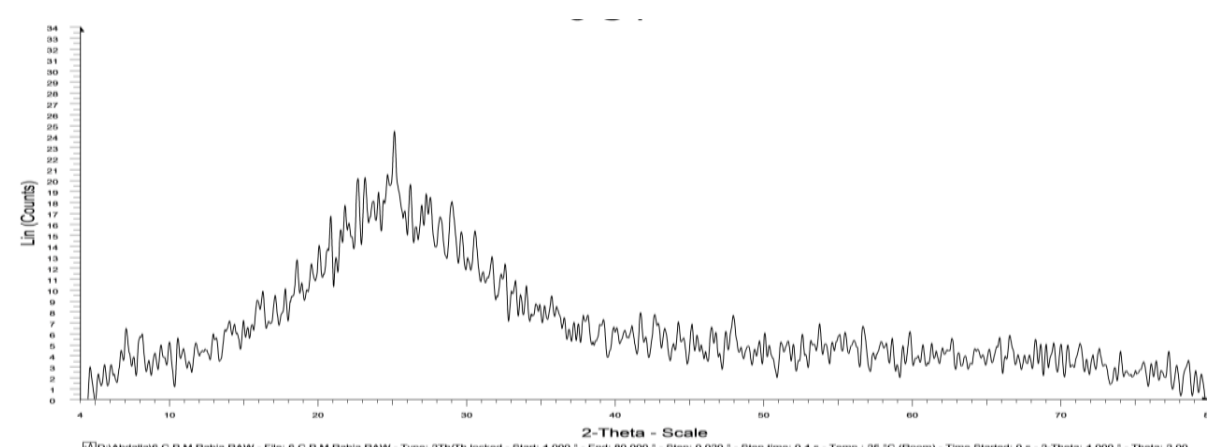

Figure. 12. (a) Top-view FE-SEM image and (b) XRD of p(o-cresol-co-pyrrole) Prepared at the optimum condition 


\section{CONCLUSION}

In conclusion, the electropolymerization of o-cresol-co-pyrrole on pt electrode is a novel copolymer was synthesized notoriously complex process which depends on the comonomer structure, the potential scan rate and the temperature. The optimum concentrations of acid and monomer are 0.3 and $0.05 \mathrm{M}$, respectively. From the kinetic studies of the electropolymerization, the orders of the reaction with respect to acid and monomer concentrations are 1.1 and 2.3 respectively. In addition, the apparent activation energy, enthalpy and entropy are estimated to be $27 \mathrm{~kJ} / \mathrm{mol}$, be $17.9 \mathrm{~kJ} \mathrm{~mol}^{-1}$ and $12.6 \mathrm{JK}^{-1} \mathrm{~mol}^{-1}$, respectively.. The morphology, structure and chemical composition of the obtained copolymer are studied by SEM, XRD, IR, UV, TGA and elemental analysis. The electropolymerized film which was the spherical aggregates were of quite uniform size with a diameter range from $200-400 \mathrm{~nm}$. Moreover, the mechanism of the process is proposed and discussed the copolymer structure was studied by fineman Ross method and the copolymer was found to be block copolymer.

\section{REFERENC}

[1] P.N.Bartlett, R.G. Whitaker, Electrochemical immobilisation of enzymes: Part I. Theory, Journal of Electroanalytical Chemistry and Interfacial Electrochemistry, 224, 27-35

P.N. Bartlett, R.G. Whitaker, Electrochemical immobilisation of enzymes: Part II. Glucose oxidase immobilised in poly- $N$ methylpyrrole, Journal of Electroanalytical Chemistry and. Interfacial Electrochemistry, 224, 1987, 37-48

[3] S.Sadki, P. Schottland, N. Brodie, G. Sabouraud, The mechanisms of pyrrole electropolymerization, Journal of Chemical. Society Reviews, 29, 2000, 283-293

[4] O.Yehezkeli, Y.-M.Yan, I.Baravik, R.Tel-Vered, I. Willner, Integrated oligoaniline-cross-linked composites of Au nanoparticles/glucose oxidase electrodes: A generic paradigm for electrically contacted enzyme systems, European Journal of Chemistry, 15, 2009, 2674-2679

[5] J.Bai, S.Beyer, D. Trau, Conjugated polymers for biosensor devices, Journal of Comprehensive Biomaterials; Ducheyne, P., Ed.; Elsevier: Oxford, UK, 2011, 529-556

[6] H.Zhou, H.Chen, S.Luo, J. Chen, W.Wei, Y.Kuang, Preparation and bioelectrochemical responses of the poly(mphenylenediamine) glucose oxidase electrode, Journal of Sensors \& Actuators, B: Chemical, 101, 2004, 224-230

M.Badea, A.Curulli, G. Palleschi, Oxidase enzyme immobilisation through electropolymerised films to assemble biosensors for batch and flow injection analysis, Biosensors \& Bioelectronics, 18,2003, 689-698

[8] P.N.Bartlett, D.J. Caruana, Electrochemical immobilization of enzymes. Part V. Microelectrodes for the detection of glucose based on glucose oxidase immobilized in a poly (phenol) film, Journal of Analyst, 117, 1992,1287-1292

[9] P.N. Bartlett, D.J. Caruana, Electrochemical immobilization of enzymes. Part VI. Microelectrodes for the detection of L-lactate based on flavocytochrome b2 immobilized in a poly(phenol) film, Analyst ,119,1994, 175-180

[10] T.T.-C.Tseng, J.Yao, W.-C. Chan, Selective enzyme immobilization on arrayed microelectrodes for the application of sensing neurotransmitters, Journal of Biochemical Engineering, 78, 2013, 146-153

O. Karunwi, A.N.Wilson, C.N.Kotanen, A. Guiseppi-Elie, Engineering the abio-bio interface to enable more than moore in functional bioelectronics,Journal of Electrochemical Society,160, 2013, B60-B65

C.Apetrei, M.L.Rodríguez-Méndez, J.A. De Saja, Amperometric tyrosinase based biosensor using an electropolymerized phosphate-doped polypyrrole film as an immobilization support. Application for detection of phenolic compounds, Journal of Electrochimica Acta,56, 2011, 8919-8925

[13] A. Guiseppi-Elie, Chemical and Biological Sensor Devices Having Electroactive Polymer Thin Films Attached to Mirofabricated Devices and Possessing Immobilized Indicator Moieties, U.S. Patent No. 5,766, 1998,934

[14] A.Guiseppi-Elie, S.Brahim, A.M. Wilson, Biosensors based on electrically conducting polymers. In Handbook of Conducting Polymers: Conjugated Polymer Processing and Applications, 3rd ed; Skotheim, T., Reynolds, J.R., Eds.; Taylor and Francis: New York, NY, USA, 2, 2007, 12:11-12:45

[15] S. Cosnier, Biomolecule immobilization on electrode surfaces by entrapment or attachment to electrochemically polymerized films. A review, Biosensors and Bioelectronics ,14,1999, 443-456

[16] M.Gattrell , D.W.Kirk ,A study of electrode passivation during aqueous phenol electrolysis, Journal of Electrochemical Society, $140,1993,903-911$

[17] M .Gattrell, D.W.Kirk, A Fourier Transform Infrared Spectroscopy Study of the Passive Film Produced during Aqueous Acidic Phenol Electrooxidation.Journal of Electrochemical Society,139, 1992, 2736

[18] M. S. Ureta-Zanatru, P. Bustos, C. Berrios, M. C. Diez, M. L. Mora, C. Gutierrez, Electrooxidation of 2,4-dichlorophenol and other polychlorinated phenols at a glassy carbon electrode,Journal of Electrochimica Acta ,47,2002, 2399

[19] P. Randless, Graphical solution of linear sweep voltammetry,Journal of Transactions of the Faraday Society,44,1984,327

[20] A. Sevick , Oscillographic polarography with periodical triangular voltage,Journal of Collection of Czechoslovak Chemical Communications, 13,1948, 349

[21] H.Karamil,A. R. Nezhad, Investigation of Pulse-Electropolymerization of Conductive Polypyrrole Nanostructures , International Journal of Electrochemical. Science, 8,2013, $8905-892$

G. Arslan, B. Yazici, Me. Erbil,The effect of $\mathrm{pH}$, temperature and concentration on. electrooxidation of phenol, Journal of Hazardous Materials ,B124,2005,37-43

H.Eyring ,TheActivated Complex in Chemical Reactions. Journal of Chemical Physics, 3 (2) , 1935, 107

M.Finman , S.D.Ross, Linear method for determining monomer reactivity ratios in copolymerization, Journal of Polymer Science, $52,1950,50$ 